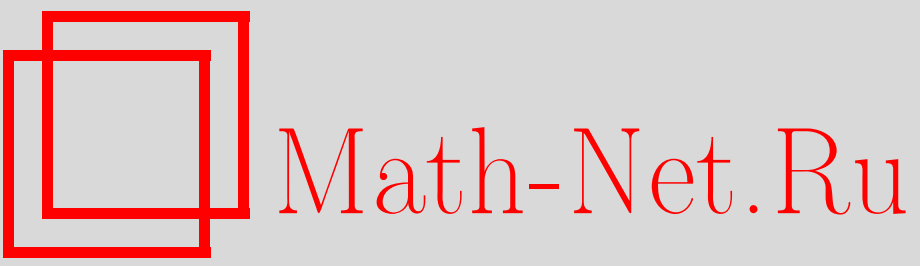

В. И. Иванов, Б. С. Кашин, С. А. Теляковский, Международная конференция "Теория приближений и гармонический анализ", УМН, 1999, том 54, выпуск 2, 205-207

DOI: https://doi.org/10.4213/rm1621

Использование Общероссийского математического портала Math-Net.Ru подразумевает, что вы прочитали и согласны с пользовательским соглашением

http://www. mathnet.ru/rus/agreement

Параметры загрузки :

IP : 54.84 .234 .179

26 апреля 2023 г., 17:02:25 


\section{МЕЖДУНАРОДНАЯ КОНФЕРЕНЦИЯ “ТЕОРИЯ ПРИБЛИЖЕНИЙ И ГАРМОНИЧЕСКИЙ АНАЛИЗ”}

С 26 по 29 мая 1998 года в Туле проходила Международная конференция "Теория приближений и гармонический анализ", организованная Тулским государственным университетом, Математическим институтом им. В. А. Стеклова РАН и Московским государственным университетом им. М. В. Ломоносова. Этим была продолжена традиция проведения в нашей стране международных конференций по теории приближений. Ранее такие конференции состоялись в Калуге (1975 и 1996 гг.) и Киеве (1983 г.).

Для формирования научной программы конференции был создан Международный программный комитет во главе с академиком С. М. Никольским.

Председателем Оргкомитета конференции был ректор ТулГУ, профессор Э. М. Соколов, заместителями председателя - авторы настоящей статьи.

В Тульской конференции приняли участие 152 ученых из 6 стран: Азербайджан (2), Беларусь (2), Израиль (1), Казахстан (2), Россия (126), Украина (19). Распределение участников по городам: Тула и Тульская обл. - 49, Москва и Московская обл. - 36, Днепропетровск - 8, Екатеринбург и Калуга по 5, Одесса и Ярославль по 4, Воронеж, Орел, Ростов-на-Дону, Санкт-Петербург и Саратов по 3, Баку, Донецк, Киев, Махачкала и Энгельс по 2, Алма-Ата, Волгоград, Гомель, Днепродзержинск, Иваново, Караганда, Кировоград, Минск, Нижний Новгород, Озерск Челябинской обл., Пермь, Петрозаводск, Таганрог, Улан-Удэ, Харьков и Хайфа по 1.

Успешному проведению конференции способствовала финансовая поддержка ее Российским фондом фундаментальных исследований (проект № 98-01-10026). Благодаря этому удалось частично компенсировать командировочные расходы российским участникам конференции, качественно и своевременно издать тезисы докладов.

На конференции были сделаны 11 пленарных (40 мин.) и 119 секционных (20 мин.) докладов по всем основным направлениям исследований по теории приближений и гармоническому анализу, проводимым в России и странах СНГ. Среди докладчиков - один академик НАН Украины, один член-корреспондент РАН, один член-корреспондент НАН Казахстана, 45 докторов и 66 кандидатов наук, 21 аспирант и 15 студентов.

В докладах, посвященных классическому направлению теории приближений - приближению функций полиномами в действительной и комплексной областях, рассмотрены поточечное приближение и приближение в метрике $L_{1}$ функций из классов $W^{r}, W^{r} H^{\omega}$ (В.П. Моторный, А.М. Коган); равномерная аппроксимация функций многочленами с ограничениями (положительными коэффициентами) (Р.М. Тригуб); аппроксимация функций с переменной гладкостью (И.И. Шарапудинов); новый подход к изучению некоторых аппроксимационных величин (В.В. Жук); аппроксимация положительными операторами (В. С. Виденский, Р. К. Васильев); аппроксимация в метрике $L_{p}$ на кривых в комплексной области (Д. И. Мамедханов); базисность и минимальность полиномиальных систем в пространстве целых функций экспоненциального типа (В.А. Осколков); распределение значений случайных тригонометрических полиномов (А.Г. Карапетян и С. В. Конягин); построение ортогональных многочленов на системе отрезков (А. Л. Лукашов, А.Б. Богатырев); экстремальные свойства многочленов (Р. Р. Акопян); применение многочленов Ахиезера для построения оптимальных методов решения систем линейных уравнений (В.А. Клячин). 
В докладах, посвященных приближению сплайнами, рассмотрены аппроксимация двумерными сплайнами гладкости два, являющимися многочленами на треугольниках (Н. Л. Зматраков); интерполяция сплайнами нецелого порядка при приближенном решении уравнений математической физики (А.А. Женськбаев); единственность сплайна наилучшего несимметричного приближения в метрике $L_{1}$ (О.В. Поляков); восстановление функций двух переменных с помощью биквадратических сплайнов с использованием интерлинации (И. В. Крыкова); нелинейная сплайн-аппроксимация в диадических пространствах Бесова (И. П. Иродова).

Несколько докладов было посвящено исследованию всплесков: построению модифицированных локальных всплесков Добеши (И.Я. Новиков); построению в соболевских пространствах $W_{2}^{m}\left(\mathbb{R}^{n}\right)$ базисов всплесков, реализующих колмогоровские поперечники (В. Л. Дольников и Н.А. Стрелков).

В докладах, посвященных приближению рациональными дробями, рассмотрены поведение элементов таблиц Паде и Чебышёва индивидуальных функций (А.П. Старовойтов, С.А. Луговской); аппроксимация в пространствах $L_{p}$ некоторых классов аналитических функций (Н.С. Вячеславов); аппроксимация на полуоси функций вида $1 / f$, где $f$ - аналитическая функция (П. А. Шулиманов).

Часть докладов была посвящена теоремам вложения (Ю.А. Брудньй) и приближению функций многих переменных: приближению в пространстве $L_{2}$ с весом гиперболическим углом (Т.Ю. Куликова); приближению полиномами и определению различных модулей гладкости на сффере (А.П. Терехин); нахождению равномерного уклонения многомерных сумм Фавара на классах Липшица (Д.В. Горбачев).

Многие доклады были посвящены теоремам Джексона. Теоремы Джексона с неточными константами установлены в пространстве $L_{2}\left(\mathbb{R}_{+}, x^{\alpha} d x\right)$ для модулей непрерывности, определяемых с помощью оператора обобщенного сдвига Бесселя (С. С. Платонов); в пространствах $C(T)$ и $L_{2}(T)$ для модуля непрерывности, аннулирующего тригонометрические полиномы фиксированного порядка (А.Г. Бабенко, Н.И. Черных, В.Т. Шевалдин); в обобщенных пространствах Орлича (А. В. Медведев). Теоремы Джексона с точными константами установлены в пространстве $L_{2}\left(\mathbb{R}^{n}\right)$ (А. Г. Бабенко); в пространствах $L_{p}\left(\mathbb{R}^{n}\right), 1 \leq p<2$ (А.В. Московский); в пространстве $L_{2}$ на гиперболоиде (Д.В. Горбачев, М. С. Пискорж); в пространстве $l_{2}\left(\mathbb{Z}_{4}^{n}\right)$ (О.И. Смирнов, А.А. Тюрюканов). Установлена связь между оптимальной точкой в неравенстве Джексона в $L_{2}\left(\mathbb{R}^{n}\right)$ и одной экстремальной задачей типа Логана для целых функций $n$ переменных (Е.Е. Бердышева).

Были доклады, посвященные классической проблематике теории функций: тауберовы теоремы для интегральных преобразований (Ю.Н. Дрожжинов), равномерная сходимость рядов Дирихле (Ю. Ф. Коробейник).

Некоторые доклады были посвящены экстремальным задачам на сфере: задаче Коревара (В.А. Юдин); о связи между кодами и дизайнами (Д. В. Горбачев, В.И. Иванов); нахождению контактного числа в $\mathbb{R}^{4}$ (В.В. Арестов, А. Г. Бабенко), а также геометрическим характеристикам банаховых пространств (И.Г. Царьков).

Интерес вызвали доклады, посвященные экстремальным задачам о колмогоровских поперечниках классов дифференцируемых функций (В. М. Тихомиров); об относительных поперечниках по Коновалову (Ю.Н. Субботин и С. А. Теляковский); о неравенствах Колмогорова для функций многих переменных (В.Ф. Бабенко, Г.Г. Магарил-Ильяев); информационных поперечниках и сложности задачи восстановления операторов (Н.П. Корнейчук).

В докладах, посвященных разложению функций по ортогональным системам, рассмотрены возможность обобщения теорем об исправлении функций (Б. С. Кашин); сходимость почти всюду, по мере и в метрике $L$ кратных рядов Уолша (С. Ф. Лукомский); единственность кратных рядов Уолша (Н.Н. Холщевникова); новые достаточные условия интегрируемости кратных тригонометрических рядов (О.И. Кузнецова); новые условия сходимости в среднем тригонометрических рядов Фурье (А.С. Белов); условия сходимости рядов из коэффициентов Фурье периодических функций многих переменных (Г.А. Акишев); абсолютная и равномерня сходимость тригонометрических рядов Фурье классов $H_{p}^{k}[\omega]$ (Н.А. Ильясов); анализ Фурье фрактальных мер (А.А. Рябинин); необходимые условия сходимости рядов Фурье по мультипликативным сис- 
темам (В.И. Щербаков); условия существования нуль-рядов по системе Уолша (В.В. Костин, В. А. Скворцов); условия наилучшей сходимости частичных сумм ортогональных рядов (А. И. Рубинштейн); приближение кратными ортогональными рядами (В.А. Андриенко); полнота в пространстве $L$ систем, близких к системе Хаара (В. И. Филиппов); слабая обобщенная локализация кратных рядов Фурье (Т. А. Мацеевич).

Некоторые доклады были посвящены разложению функций по системам, близким к ортогональным: построению обобщенных ортоподобных систем (Т. П. Лукашенко); суммируемости методами Чезаро ортоподобных разложений (А.Н. Павликов); существованию сходящихся почти всюду перестановок ортоподобных разложений (Т.В. Родионов).

В докладах, посвященных интегральным операторам, рассмотрены поведение преобразования Харди вблизи $L_{\infty}$ (В.А. Родин); двоичные аналоги операторов Харди и Харди-Литлвуда (Б.И. Голубов); интеграл Фурье для функций ограниченной $\Lambda$-вариации (А. Н. Бахвалов); неограниченность некоторого класса максимальных операторов (Г.В. Арутюнянц); оценки невозрастающей перестановки некоторой максимальной функции (А. К. Лернер).

Часть докладов была посвящена изучению различных обобщений интеграла Римана: интегрированию по частям в интеграле Хенстока (К.М. Нараленков); взаимоотношению интегралов Бохнера и Макшейна в случае бесконечномерности пространств значений интегрируемых функций (А.П. Солодов).

В докладах, посвященных приложениям, были рассмотрены применение систем Крестенсона-Леви в цифровой обработке информации (А.В. Ефимов); применение метода конечных элементов при решении задач механики деформируемого твердого тела. Цикл докладов был посвящен применению теорем вложения при изучении уравнений в частных производных.

Конференция проводилась на базе дома отдыха "Ясная Поляна" вблизи музея-усадьбы великого русского писателя Л.Н. Толстого, что создавало в ее работе особый настрой.

Участникам конференции была предоставлена возможность познакомиться с Тулой, ее знаменитыми музеями самоваров и оружия, посетить музей-усадьбу "Ясная Поляна".

По обшему мнению конференция прошла успешно. Участники отмечали высокий уровень докладов и четкую организацию конференции. Высказывались пожелания следующую Международную конференцию по теории приближений и гармоническому анализу провести в 2000 году.

Избранные труды по материалам докладов, сделанных на конференции, опубликованы в специальном выпуске журнала "Известия ТулГУ. Серия Математика. Механика. Информатика", т. 4, вып. 1, Тула, 1998.

Информация о конференции (тезисы докладов, список участников, программа) размещена в Internet по адресу: http://win.home.uic.tula.ru/ ${ }^{\text {so/approx } 98 /}$

В.И. Иванов, Б.С. Кашин, С.А. Теляковский 